\title{
Social Causes to Sickness Absence among Men and Women with Mental Illnesses
}

\author{
Kari Batt-Rawden ${ }^{1}$, Gunnar Tellnes ${ }^{2}$ \\ ${ }^{1}$ Eastern Norway Research Institute, (Østlandsforskning), Lillehammer, Norway \\ ${ }^{2}$ Institute of Health and Society, University of Oslo, Oslo, Norway \\ Email: kbr@ostforsk.no
}

Received January $10^{\text {th }}$, 2012; revised February $14^{\text {th }}$, 2012; accepted March $15^{\text {th }}, 2012$

\begin{abstract}
Introduction: The mental ill-health diagnoses seem to be increasing in Europe and there are global trends towards increasing stress and ill-health at work. In order to understand the social situation for the sickness absentees it is important to consider how identities and relationships are formed in interaction with other people. Aims: 1) To reveal the absentees own perceptions and experiences of being on sick leave; 2) To understand and uncover the absentees' own views of the causes of their illnesses. Methods: This study takes an exploratory approach, examining an area where there has been little data and building upon work that has focused on sickness absence as a phenomenon. It attempted to do so through a pragmatic synthesis of elements of ethnography and grounded theory. The main study concentrates on two main groups of diagnoses: musculoskeletal and mental problems. A sample of 30 persons on sickness absence was selected from the county of Oppland, Norway. 14 were diagnosed with musculoskeletal problems and 16 with mental illnesses. This paper deals with one main group; mental illnesses. Seven men and nine women from the county of Oppland, Norway were diagnosed with mental illnesses in accordance with the ICD-10 medical classification system $(n=16)$. Results: Women experience family burdens and caring responsibilities as social factors to their sickness absence, often due to a lack of support and constant burden from both work and home. Men experience stress and conflicts at work, mostly from the leadership and its organizational structure. Conclusion: A holistic approach that considers the whole life situation must also be considered in order to understand gender differences in sickness absence. Furthermore, to investigate what can be done to reduce long-term sickness absence that is not caused by traditional somatic or severe psychological disorders.
\end{abstract}

Keywords: Mental Illness; Health; Social Causes; Sickness Absence; Coping; Burden; Stress

\section{Background and Current Research on Sickness Absence Due to Mental Diagnoses}

The mental ill-health diagnoses seem to be increasing in Europe (Järvisalo et al. 2005), and there are global trends towards increasing stress and ill-health at work (Dollard et al., 2007). Grey cases often arise from a long-lasting negative subjective experience, like pain, in which the medical profession has been unable to identify an underlying physical and/or pathological cause (Nordby, Rønning, \& Tellnes, 2011). There is considerable research on the relationship between the psycho-social conditions in working life in general and sickness absence in particular. In their survey of research on the effect of working conditions on mental ill health and sickness absence, Michi and Williams (2003) have found that demands such as long hours, excessive work under pressure, lack of opportunities to influence one's work situation, and poor support from managers were critical. Their results support the extensive research showing that demanding psycho-social working conditions in combination with few chances to determine how and when to work exacerbate stress, resulting in negative conesquences for employees' health (Karasek \& Theorell, 1990). Michie and William's survey also confirms previous research that has emphasized the importance of social support, which has shown that rewarding great efforts poorly is deleterious (Siegrist, 1996). It is also a well-known fact that extensive or- ganisational changes can, in certain circumstances, induce stress-related illnesses. One study from Finland, for example, has found that individuals who have recently been exposed to cutbacks and reorganization show symptoms of burnout (Kalimo, 2000). A Swedish study has also found that the risk of burnout was twice as great among those who had been exposed to organizational changes in the previous year than among those who had not (Hallsten, 2005). The organization of work is not the only important factor for employees' health; the quality of social relations is also significant for the occurrence of mental ill-health. Problems or worries at home or in the family have been reported as contributory factors resulting in sickness certification by $12 \%$ of the patients, and problems/worries during leisure time by 7\% (Tellnes, 1990). Almberg et al., (2000) have found that the feeling of not being involved in major decisions has a negative effect on the mental health of care-giving relatives. Other expressions of exclusion, such as being frozen out, belittled or having low social status, relate also to mental ill-health (Billeter-Koponen \& Fredén, 2005; Lindberg et al., 2006). A recent study by Eriksson et al. (2009) has suggested that the course of events leading to sickness absence due to burnout might be understood as a process of emotional deprivation, where the individual is gradually emptied of the life-giving emotional energy that is expressed as joy, commitment, and empathy. The process began in connection with unresolved 
conflicts, which arose as a result of radical organizational changes that have continued to escalate (Eriksson, Starrin, \& Janson, 2008). There are, then, various models at the communal, organizational, and individual levels that help to explain the contributory factors of mental ill-health.

In order to understand the social situation for the sickness absentees it is important to consider how identities are formed in interaction with other people. We know from the literature that the label of mental illness is linked to an array of negative stereotypical traits and that people with a mental diagnosis run the risk of being stigmatized (Corrigan \& Lundin, 2001; Scheff, 1966). One distinguishing feature, considered to be stigmatizing, is that these groups are particularly subjected to shaming in the form of humiliation, belittling, and condescending and patronising treatment. Many people would regard them as being of lesser value. Having been condescended seems to be strongly associated with long-term sickness absence with a mental diagnosis (Engstrøm \& Eriksson, 2011). People with mental illness suffer the most from stigma. Stigma robs people of their rightful life opportunities, such as employment and housing. In a study of the relations between social loss, humiliation, and depression, show that humiliation seems to be as significant a factor in explaining depression as social loss. Further, these factors taken together constitute a tangible risk for severe depression. Still other studies show that the experience of shaming in the form of humiliation is a significant cause of depresssion (Brown, Tillis, \& Hepworth, 1995) and that shaming covaries with mental ill-health among those on social assistance (Starrin, Kalander, Blomqvist, \& Janson, 2003) and the unemployed (Starrin \& Jönsson, 2006; Rantakeisu, Starrin, \& Hagquist, 1999). Moreover, in order to understand the nature of sickness absence, we need research with different perspectives and a focus on the different sides of the phenomenon. Recent research also shows how nature-culture experiences, including a salutogenic perspective, may help people with long term illnesses to construct experienced life meaning, identify coping mechanisms and strengthen the self (Batt-Rawden \& Tellnes, 2010, 2011).

\section{Aims of the Study}

The purpose of our project is to focus on and to discuss how social factors influence sickness absence. Our study concentrates on two main groups of diagnoses: musculoskeletal and mental health problems. Our approach is concentrating on individual attitudes and understandings and how they are created in social interaction. We are also concerned with how men and women understand and interpret their situation differently. Of special interest to this study are the attitudes to different kinds of mental diagnoses. Moreover, to reveal the absentees own perceptions and experiences of being on sickness absence with mental diagnoses.

\section{Methodological Approach}

This study takes an exploratory approach, examining an area where there has been little data and building upon work that has focused on sickness absence as a phenomenon. To realize the objectives described in the previous section, this exploratory study sought to elicit informants' life stories and to instigate narratives about the role of being long term ill. It attempted to do so through a pragmatic synthesis of elements of ethnography and grounded theory. The ethnographic interview is one strategy for getting people to talk about what they know and this study was ethnographic insofar as it sought to document the informants' own meanings derived from and applied to illness and sickness absence. Moreover, to set these meanings in the contexts of the informants' lived experience (Hammersly \& Atkinson, 2000; Ritchie \& Lewis, 2003).

Inspired by grounded theory, the research questions attempted to explore and describe social processes of illness and health as they emerged from the ethnographic data (Glaser 1978; Starrin, Dahlgren, Larsson, \& Styrborn 1997). The inductive nature of grounded theory methods assumes an open, flexible approach, shaping methodological strategies while engaged in the research, rather than having them planned before beginning the data collection. Grounded theory seems to be the approach most suited to the study of informants' own meanings and practices by using an open-ended interview guide. This notion of flexibility is important to let themes emerge from the informants' own accounts (Charmaz, 2003). Recurrent themes can be described as themes that both occur several times within one participant and/or among the sample as a whole. The first major analytic phase of the research consisted of coding the data through open coding in order to identify descriptions of thoughts and ideas related to the interview questions. To generate categories and subcategories, "focused" coding was used to compare between incidents, contexts and situations, and connections between incidents, situation and categories were explored.

\section{Recruiting and Selecting a Convenient Sample}

The interviewees were selected from the Norwegian Labour and Welfare Administration [NAV] in Norway, following the inclusion criteria: an employed woman or man between 20 and $50+$ (from two generations) who has an ongoing sickness absence period exceeding 31 days or a currently expired period, with a mental or a musculoskeletal diagnosis in accordance with the ICD-10 medical classification system. The sample was selected from the county of Oppland, and 30 Norwegians (20 women and 10 men) made contact with the researchers through phone or e-mail before the interviews were conducted. By sending information letters to potential informants, describing the study and the researcher's names, emails and phone numbers, it was up to the informants themselves to initiate the first contact with the researchers, thus the willingness and motivation from the informants to dedicate time and effort to the study can be described as a convenience sample (Charmaz, 2003).

\section{Sample}

The informants were distributed as follows: Two men were in their thirties, five men in their forties and three men were in their fifties. Among the women seven were in their fifties, and eight in their forties. Three women were in their thirties and two were in their twenties. Out of the total sample $(n=30)$ seven men and nine women were diagnosed with mental illnesses; hence depression and anxiety or burn out $(\mathrm{n}=16)$ and presented in this paper. Before the interviews, all participants were informed about full confidentiality and about their right to break off participation at any time. The participants were asked to sign an informed consent document. The interviews lasted for about one to two hours per informant, audio-taped and tran- 
scribed verbatim.

\section{Results}

Recurrent patterns and tendencies showed how men and women's mental illnesses were substantiated in complex, problematic and complicated relationships over time. However there seems to be a clear pattern: Women experience family burdens and caring responsibilities as social factors to their sickness absence, often due to a lack of support and constant burden from both work and home. Men experience stress and conflicts at work, mostly from the leadership and its organizational structure. Opposed to women, men describe seldom problems with caring responsibilities or family burdens.

\section{Social Factors among Women Leading to Illness- Family Burdens and Strains}

All women in this study describe their stories of being ill as slightly more complex and long-lasting then men, sometimes grounded in a complicated and conflict ridden upbringing. This might be due to drug abuse, violence, high level of relational conflicts, lack of recognition and neglicance during childhood. A female informant (age 39) describes how she felt a sudden burn-out and how her illness progressed highly unexpectedely. She elaborates her problems as caused by an authoritative grandfather during her upbringing: It came very sudden, I felt I hit the wall, and I couldn't manage to go to work, and this came as a schock, and then the feeling of shame. The reasons behind my depression, I think, is due to my grandfather who was very authoritative, and he is the cause of my lack of selfconfidence and self efficacy. It was so scary being so ill, like a big gap.

It looks as if women who has been exposed to relational problems and conflicts, quite often has experinced mental health problems and illnesses over time. These life events seem to have effected ways to master the challenges and burdens in daily life. One female (age 60) believes her mental illness is substatiated in her relationship with her mother, one that was full of criticism and negative comments, and few postive and constructive feedbacks on herself. Her self-confidence and self efficacy was destroyed by being constant criticised. I have always been a kind of clever girl, and I have always had this internal pressure in me to cope with challenges and strains in everyday life, and as a young girl I did not have any postitve feedback or reassurance from my family from what I did or achieved, and that ruined my self-confidence...

Additionally, some of these women have had various personal crisis due to their childrens severe illnesses, drug problems and sexual harassment. A female informant (age 54) describes her mental illness as related to a traumatic divorce, thus her story of being ill relates back to a long lasting internal pressure of a dysfunctional and pathological marriage. Two of three children were also affected by the instability and disharmony in the familiy whom had developed mental and somatic problems. She also had an ongoing and unresolved conflict at work at the time of the interview. It was a very difficult marriage, and he punished my daughter when I left him, causing her to be totally exhausted, and then she became ill, and I have a son who has had mental health problems since he was young, and he blames his father for being the cause of it.

Another woman (age 53) had a daughter who was a heroin addict, and a cohabit who also had a son who had drug problems and died of an overdose. She describes how she experinced her role in the family and her effort to knit a problematic famliy life together as unsuccessful, neglecting her own needs. She managed to keep her job whilst the family had the toughest time. However, today she is diagnosed with a depression due to familiy burdens and strains over a long period in her life: Someone had to knit or hold the family togehter, so I did not take any heed to my self nor did I listen to my body telling me I ought to take a long break, I only headed on in full spate. Sara (age 40) claims that her depression is clearly related to the fact that her daughter was sexually abused for several years by a close friend. She realized she could neither cope with her caring responsibilities nor manage to take care of herself. Being divorced from her husband with whom the children had sparsley contact with, she had a severe break down followed by being diagnosed with depression: I feel a lack of energy, I am sleepless and I feel I am on call all the time.

\section{Social Processes among Men Leading to Illness- Work and Stress}

In recent years some employees have met new challenges at work, substantiated in organizational and structural changes, pressuring people to produce and be more effective in shorter time. For many men in this study a high tempo job with less control and flexibility combined with an effort to meet the rapid changing working climate, several of the male informants feel an increase in stress levels. Through the demands of work incorporating new technologies, new tasks and insecure jobs, some work places seem to instigate procesess that may lead to burn out and sickness abcence. One male informant (age 57) describes his job as one that he gradually became alienated from. With new owners he felt his work effort was surplused, and not appreciated and worthy. In 2008 we had to reduce our staff, and the owners seemed further and further away from us. It's only the money that counts... since the new leadership took over we have heard that they really don't want us. We are too many, they say... You really feel that you are not worthty anything, we are only a huge cost...

Several male informants tell stories of how strong and inhuman pressure at work can lead to conflicts between the leadership and the employees. A male informant (age 42) who has worked at the same company for many years, observed how the staff were reduced and how employees felt difficulties in coping with the ongoing changing realities at work: Quite often we read in the newspaper about changes at our work before we are informed about cutbacks in staff. We always get negative criticism and feedback from the leadership, and they always pinpoint on how we all should achieve better, be more productive and earn more money for the company like machines we are... Strong pressure at work may lead to lack of motivation for work, and along with a neagtive spiral of deteriorating processes, the employees run the risk of being long-term ill. These negative, social processes at work seem to be followed by indifference, bad perfomance, lack of motivation, satisfaction, fatigue and apathy by the employees. These elements are illustrated through this voice (age 59):

I remember so well the day before I went on sickness absence... I had some relatives visiting and we were going to have a nice week-end, and I felt so tired and deflated, and during the night I said to myself, that this can't go on... I realised my lim- 
its...

If a leader does not follow up an employee who has developed health problems due to psycho-sosical factors at work, this may lead to an extended period of sickness absence and possibly a signing up; After I had been on sickness absence for a long time, I felt that the cup was full and I had to resign...

\section{Discussion}

\section{Methodological Considerations and Limitations}

The research data needs to be set in context. It was collected from the population of a mid-eastern region of Norway comprising the county of Oppland. In line with a qualitative approach, any conclusions drawn from the sample cannot be generalised to the population as a whole, though through a series of similar studies more general conclusions may well emerge. In this sense, this sample is a convenience sample which is not statistically representative; nevertheless, some tentative general conclusions may be proposed. It may be difficult to assess why it seemed so difficult to recruit a convenient sample. One reason may be because potential informants were too ill to participate in the study. The invitation letter also included a request to sign a written consent which was voluntarily. Moreover, people who are ill may refuse to join the study due to lack of energy, motivation or personal reasons.

\section{Validity and Reliability}

Qualitative researchers vary considerably in their attitudes to the issue of the "representativeness" of their material and are sometimes accused of failing to satisfactorily demonstrate the reliability and objective validity of their data and findings (Charmaz, 2003; Hallberg, 2002). In qualitative research reliability and validity are discussed in terms of "adequacy of evidence" and "trustworthiness". Reliability or "adequacy of evidence" is reached when similar relationships between phenomena or themes frequently emerge from the data. Validation or trustworthiness of the developing theory is based on constant comparison. From this viewpoint, the rationale of this approach is to fully exploit one of the principal merits of qualitative meaning in depth and in and through different life phases, events and situations, here illustrated through the informants own voices. It seemed as if all of them had an agenda, a life story to tell. The fact that each participant was only interviewed once might have contributed to minor trust and confidence between participants and researcher. Another aspect of one-off interview is the inability to check certain accounts or repeat questions, helping to clarify and identify emerging and recurrent themes, issues and topics. However, the impression was that the informant's beliefs and opinions were genuine and real, though their verbalism did vary (Hammersley \& Atkinson, 2000; Thagaard, 200; Ritchie \& Lewis, 2003; Smith, 2003).

In qualitative studies it is important to reflect upon and consider the role of the researcher: i.e. the researcher's gender, age and personal characteristics have been taken into account (Smith, Dennis, \& Johnson, 1997; Schensul, Schensul, \& LeCompte, 1999). The informants were also able to choose time and place of the interviews, and this flexibility seemed to be very well received. The interviews were held in private homes, cafes', libraries and at a research office. It was however interesting to detect that there seemed to be no particular connec- tion between verbal flow of communication and place of interview.

\section{Deteriorating Mental Health Processes among Women}

The women in this study claim to have insight and personal opinions considering the development of their own illnesses. It seems to be a general pattern as to how these women have a lack of positive criticism, affirmation and acknowledgement in their upbringing. Combined with authoritative and dominant persons in their social network who may have had a negative impact on their self-esteem, self-confidence and self-efficacy, these factors may have been vital for developing their mental health illnesses. Moreover, problematic life events and caring responsibilities along with low support from relatives, seem to have left some of the women alone with family tasks and burdens. Previous research also show much higher odds ratios for women working in high strain jobs, as compared to men with similar working conditions and requires further discussion A possible explanation; the combined impact of domestic responsibilities and job strain, the so-called double exposure (Engstrøm \& Eriksson, 2011). For example, Swedish women carry out about two thirds of all unpaid work related to the home (Krantz \& Östergren, 2001). In the case of a woman working in a high strain job, this double exposure could have an added impact on a declining health and, by extension, sickness absence. Another recent study on sickness absence among employees in a nursing home in Norway also illustrates how work overload seems to be the dominant reason for sickness absence, though, for some, a problem in the private sphere was the determining factor. The role of being certified as sick influenced the participants' identity and made them vulnerable to being stigmatized (Batt-Rawden \& Solheim, 2011). Negative stress occurs when there is incongruence between the external demands and the individuals' needs and abilities. Our study supports previous findings (Batt-Rawden \& Solheim, 2011; BattRawden \& Tellnes, 2005), highlighting how a complicated work and life situation decreases individuals' health. In this sense, illness is a disruption not only of structures of explanation and meaning for these participants, but also of the maintenance of normal relationships and the mobilization of resources. This notion of a total life burden perception includes a traditional division of labor in the family, leaving women with little or no social or practical support. Despite equality in sex roles in recent years, it still seems that men and women execute traditional tasks in the family. In other words, for women it seems to be the total work burden that results in sickness absence. If women are left with an overall responsibility for family member's health and well-being, they neglect their own health and well-being to such an extent that they become ill. From this perspective, family relational conflicts may affect women's health more than men, since men did not proclaim these issues in this study. Accordingly, sometimes conflicts at work along with family conflicts can be too much to handle for some women. Recent studies also show how the family situation proved important, hence indicating that family conditions like cohabitation and the presence of children might add to the workload and stress experienced by employees (Lidwall, 2010; Johansen \& Rønning, 2011). Problematic life events including family members' serious illnesses also seem to put womens' health at risk, making women less capable of handling and 
coping with the challenges in everyday life. Illness among family members have been reported by $41 \%$ of patients to worsen mental health problems in general practice (Tellnes, Fugelli, \& Bjørndal, 1987). It also seems that many of the women has been socialized into a typical "clever-girl"-syndrome; that is a lack of putting down limits and always be available for other peoples wants and needs. Neglecting their own needs seem to prevent them from the possibility to refuel their energy levels. By using their resources to fulfill social expectations and demands from significant others, inherent in a traditional view of a woman's role, they ask for help too late.

\section{Deteriorating Mental Health Processes among Men}

Most men in this sample have become ill due to work related factors, although a couple of men refer to additional problems due to sudden death in the family. However, it seems to be a strenuous work, high stress levels, low control and little support from the leadership or colleagues that lead to an ill health. Feelings of disempowerment and alienation from important decisions and discussions related to organizational and structural changes at work, seem to be the most important issue raised here. It looks as if the leadership does not have strategies to handle difficult organizational and structural changes at work, it may leave the employees frustrated and incapable to act and control their own job situation. It is well know that organizational changes at the workplace along with hierarchical leadership and disempowerment of employees may lead to sickness absence. A positive self-evaluation, and a positive evaluation by others are strong motives for most people, and many people go to great pains to protect, or enhance their self-worth (Semmer et al., 2007). Moreover, threats to self-esteem, can play a major role for experiencing stress (Lazarus, 1999) in line with the men in this sample. Social support does play a prominent role in occupational stress research (Semmer et al., 2007), and as Kornhauser (1965) described a declining mental health of the industrial worker, as one that are deprived of purpose and zest. This notion may leave him with negative feelings about himself; with anxieties, tensions a sense of looseness, emptiness and futility. In this material these men seem to have lost a social meaning in their job experiences, resulting in a lack of ontological security (Giddens, 1991). In line with the Effort-Reward-Imbalance model by Siegrist (2002) which show the importance of rewards one receives for investing effort, this notion seems to be unfolded in a gap between leadership and senior employees rooted in a lack of participation. Since job satisfaction is strongly influenced by feeling appreciated (Semmer et al., 2002), condescending comments from the leadership for not being effective or productive enough, seems here to result in sickness absence.

These factors are also in line with another study (Eriksson et al., 2011) which revealed a number of critical phases and events relating to the work environment faced by all the participants. The authors describe events that contributed to an understanding of the process leading to sickness absence. This process can be described as a flight of stairs or the burnout staircase. Extensive changes in the workplace form the first step in the burnout staircase. The second step in the model is formed by insecure social bonds fraught with conflict. Increased demands form step three were noticeable both at work itself and in the relationships in the workplace. This contradictory demand forms the fourth step. The increased demands also made it more difficult to maintain a high level of quality in social contacts. The new expectations fraught with conflict produced emotional stress and affected the participants' trust in others and confidence in themselves, which is the fifth step in the burnout staircase. In step six, strong emotions and health problems became increasingly obvious. The seventh step: This collapse, however, expressed itself in different forms. Several individuals described dramatic collapses; some were able to identify triggering factors such as a confrontation at the workplace, while others could not indicate any special event. Suddenly one day, things just stopped. The body or brain ceased to function normally. The collapse was the beginning of a long period of sickness absence (step eight) (Ericsson et al., 2008). In this material there are many similarities to the "flight of stairs", for example the men described how they gradually moved towards the edge of an incident pit, sensing their situation as intolerable and unbearable. Being incapable of coping with the deteriorating processes at work, sickness absence was the only option. In line with previous research (Eriksson et al., 2011), they looked upon the sickness absence-being ill-as a failure, as something shameful. Some accused themselves for getting sick and had a bad conscience of having left their job (Suominen \& Lindstrøm, 2008). A burnout might be understood as a process of emotional deprivation, whereby the individual is gradually emptied of the life-giving emotional energy that is expressed as joy, commitment, and empathy (Eriksson, 2009; Batt-Rawden, 2010). Other studies also show a strong relationship between longterm sickness absence and the psycho-social work environment (Engstrøm \& Eriksson, 2011). Associations between sickness absence and the psycho-social work environment are also theoretically illustrated by the demand-control model (Karasek \& Theorell, 1990), and fair organizational and managerial procedures may buffer the negative effects of psychosocial health risks outside work (Elovainio et al., 2010). Previous studies also suggest that long-term sickness absence increases the risk of adverse economic and social conditions among individuals (Bryngelson, 2009).

\section{Conclusion}

Combined with discussion of sickness absence as a phenomenon, we believe our findings can contribute to a wider understanding of sickness absence, the complexity behind the outbreak of long-term illnesses and ways of coping in everyday life. From our perspective in this study and previous research, factors explaining the gender divide and patterns ought to be explored more fully. Health problems are connected to the whole person, and it may be difficult to determine the contribution of different parts in this study. A holistic approach that considers the whole life situation must also be considered in order to understand gender differences in sickness absence. Furthermore, to investigate what can be done to reduce longterm sickness absence that is not caused by traditional somatic or severe psychological disorders.

\section{REFERENCES}

Almberg, B., Grafström, M., Krichbaum, K., \& Winblad, B. (2000). The interplay of institution and family caregiving: Relations between patient hassles, nursing home hassles and caregiver's burnout. International Journal of Geriatric Psychiatry, 15, 931-939.

doi:10.1002/1099-1166(200010)15:10<931::AID-GPS219>3.0.CO;2 
$\underline{-\mathrm{L}}$

Batt-Rawden, K. B. (2010). The role of music in a salutogenic approach to health. International Journal of Mental Health Promotion, 12, 11-18.

Batt-Rawden, K. B., \& Tellnes, G. (2005). Nature-culture-health activities as a method of rehabilitation: An evaluation of participants' health, quality of life and function. International Journal of Rehabilitation Research, 28, 175-180. doi:10.1097/00004356-200506000-00013

Batt-Rawden, K. B., \& Tellnes, G. (2010). The benefits of a holistic and salutogenic approach to rehabilitation and recreation. Ecology and forests for public health (pp. 103-111). Innsbruck: International Council for Scientific Development 2010.

Batt-Rawden, K. B., \& Tellnes, G. (2011). The benefits of nature and culture activities on health, environment and wellbeing: A presentation of three evaluation studies among persons with chronic illnesses and sickness absence in Norway. In H. Nordby, R. Rønning, \& G. Tellnes (Eds.), Social aspects of illness, disease and sickness absence (pp. 199-222). Oslo: Oslo Academic Press.

Batt-Rawden, K. B., \& Solheim, L. (2011). Helpers of the fragile, elderly and sick: Report from a nursing home. In H. Nordby, \& R. Rønning, \& G. Tellnes, (Eds.), Social aspects of illness, disease and sickness absence (pp. 223-242). Oslo: Oslo Academic Press.

Billeter-Koponen, S., \& Fredén, L. (2005). Long-term stress, burnout and patient-nurse relations: Qualitative interviews study about nurses's experiences. Scandinavian Journal of Caring Sciences, 19, 20-27. doi:10.1111/j.1471-6712.2005.00318.x

Brown, G. W., Tillis, O. H., \& Cathy, H. (1995). Loss, humiliation and entrapment among women developing depression: A patient and non-patient comparison. Psychological Medicine, 25, 7-21. doi:10.1017/S003329170002804X

Bryngelson, A. (2009). Long-term sickness absence and social exclusion. Scandinavian Journal of Public Health, 37, 839-845. doi:10.1177/1403494809346871

Charmaz, K. (2003). Grounded theory. In J. A. Smith (Ed.), Qualitative psychology. A practical guide to research methods. London: Sage Publications.

Corrigan, P. W., \& Lundin, R. (2001). Don't call me nuts: Coping with the stigma of mental illness. Tinley Park, IL: Recovery Press.

Dollard, M. (2007). National surveillance of psychosocial risk factors in the workplace: An international overview. Work \& Stress, 21, 129. doi:10.1080/02678370701254082

Elovainio, M, Kivimäki, M., Linna, A., Brockner, J., Kvan den, B., Greenberg, J., Pentti, J., Virtanen, M., \& Vahtera, J. (2010). Does organisational justice protect from sickness absence following a major life event? A Finnish public sector study. Journal of Epidemiology and Community Health, 64, 470-472.

doi:10.1136/jech.2008.084301

Engstrøm, L.-G., \& Eriksson, U.-B. (2011). The impact of psychosocial work environment on sickness absence: Results from the Swedish Life \& Health 2008 Study. In H. Nordby, R. Rønning, \& G. Tellnes (Eds.), Social aspects of illness, disease and sickness absence (pp. 175-184). Oslo: Oslo Academic Press.

Eriksson, U.-B. (2010). After all you're only human-long-term sickness absence from emotional, relational and structural perspectives. $\mathrm{PhD}$ Thesis, Karlstad: Karlstad University Studies.

Eriksson, U.-B., Starrin, B., \& Janson, S. (2008). Long-term sickness absence due to burnout: Absentees' experiences. Qualitative Health Research, 18, 620-632. doi:10.1177/1049732308316024

Eriksson, U.-B., Engstrøm, L.-G., Starrin, B., \& Janson, S. (2009). Insecure social bonds at work, mental ill health and sickness absence. Work, 38, 1-9.

Giddens, A. (1991). Modernity and self-identity. Cambridge: Polity Press.

Glaser, B. G. (1978). Theoretical sensitivity. Mill Valley, CA: Sociology Press.

Hammersley, M., \& Atkinson, P. (2000). Ethnography: Principles and practice. London: Routledge.

Hallsten, L. (2005). Burnout and wornout: Concepts and data from a national survey. In A. S. G. Antoniou, \& C. L. Cooper (Eds.), Research companion to organizational health psychology. Cheltenham:
Elgar.

Järvisalo, J. et al. (2005). Mental disorders as a major challenge in prevention of work disability. Experiences in Finland, Germany, the Netherlands and Sweden. Helsinki: Kela, The Social Insurance Institution.

Johansen, V., \& Rønning, R. (2011). Social factors and long-term sickness absence: The need for a broader approach. In: H. Nordby, R. Rønning, \& G. Tellnes (Eds.), Social aspects of illness, disease and sickness absence (pp. 175-184). Oslo: Oslo Academic Press.

Karasek, R., \& Theorell, T. (1990). Healthy work, stress, productivity and the reconstruction of working life. New York: Basic Books.

Kalimo, R. (2000). The challenge of changing work and stress for human resources. The case of Finland. Journal of Tokyo Medical University, 58, 349-356.

Kornhauser, A. (1965). Mental health of the industrial worker: A Detroit study. New York: Wiley.

Krantz, G., \& Östergren, P.-O. (2001). Double exposure. The combined impact of domestic responsibilities and job strain on common symptoms in employed Swedish women. European Journal of Public Health, 11, 413-419. doi:10.1093/eurpub/11.4.413

Lazarus, R. S. (1999). Stress and emotion: A new synthesis. London: Free Association Press.

Lidwall, U. (2010). Long-term sickness absence: Aspects of society, work and family. Stockholm: Karolinska Institutet.

Lindberg, P., Josephson, M., Alfredsson, L., \& Vingård, E. (2006). Promoting excellent work ability and preventing poor work ability: The same determinants? Results from the Swedish HAKul study. Occupational and Environmental Medicine, 63, 113-120. doi:10.1136/oem.2005.022129

Michie, S., \& Williams, S. (2003). Reducing work related psychological ill health and sickness absence: A systematic literature review. Occupational and Environmental Medicine, 60, 3-9. doi:10.1136/oem.60.1.3

Nordby, H., Rønning, R., \& Tellnes, G. (Eds.) (2012). Social aspects of illness, disease and sickness absence. Oslo: Oslo Academic Press.

Ritchie, J., \& Lewis, J. (2003). Qualitative research practice. A guide for social science students and researchers. London: Sage Publications.

Rantakeisu, U., Starrin, B., \& Hagquist, C. (1999). Financial hardship and shame-A tentative model to understand the social and health effects of unemployment. The British Journal of Social Work, 29, 877-901. doi:10.1093/bjsw/29.6.877

Semmer, N. K. et al. (2007). Occupational stress research: The Stressas-Offense-to-Self. In J. Houdmont, \& S. McIntyre (Eds.), Occupational health psychology: European perspectives on research, education and practice (Vol. 2, pp. 43-60). Avioso S. Pedro: ISMAI.

Scheff, T. J. (1966). Being mentally ill III: A sociological theory. Chicago: Aldine.

Schensul, S., Schensul, J., \& LeCompte, M. D. (1999). Wicke essential ethnographic methods. London: Altamira Press.

Siegrist, J. (1996). Adverse health effects of high-effort/low-reward conditions. Journal of Occupational Health Psychology, 1, 27-41. doi:10.1037/1076-8998.1.1.27

Siegrist, J. (2002). Effort-reward imbalance at work and health. In P. Perrewe, \& D. Ganster (Eds.), Research in occupatioanl stress and well-being, hisorical and current perspectives on stress and health (pp. 261-291). London: JAI Elsevier. doi:10.1016/S1479-3555(02)02007-3

Siegrist, J. (2005). Social inequalities in health in Europe-From scientific explanations to prevention. In G. Tellnes (Eds), Urbanization and health. New challenges to health promotion and prevention. Oslo: Academic Press.

Smith, J. (2003). Qualitative psychology. A practical guide to research methods. London: Sage Publications.

Smith, S. E., Dennis, G. W., \& Johnson, N. A. (1997). Nurtured by knowledge. Learning how to do participatory action-research. New York: The Apex Press.

Starrin, B., Kalander, M., Blomqvist, K., \& Janson, S. (2003). Socialbidragstagande och statusbunden skamkänsla-En prövning av ekonomi-sociala bandmodellen. Socialvetenskaplig Tidskrift, 10, 24-47. 


\section{K. BATT-RAWDEN, G. TELLNES}

Starrin, B., \& Jönsson, L. (2006). The finances-shame model and the relation between unemployment and health. In T. Kieselbach et al. (Eds.), Unemployment and health (pp. 75-97). Brisbane, Australian Academic Press.

Starrin, B., Dahlgren, L., Larsson, G., \& Styrborn, S. (1997). Along the path of discovery. Qualititative methods and grounded theory. Lund: Studentlitteratur.

Suominen S., \& Lindstrøm, B. (2008). Salutogenese. Scandinavian Journal of Public Health, 36, 337-339. doi:10.1177/1403494808093268

Tellnes, G. (1990). Occupational factors in sickness certification.
Scandinavian Journal of Primary Health Care, 8, 37-44. doi:10.3109/02813439008994927

Tellnes, G., Fugelli, P., \& Bjørndal, A. (1987). Treatment of mental problems in general practice. Scandinavian Journal of Social Medicine, 15, 131-137. http://www.ncbi.nlm.nih.gov/pubmed/3616530

Tellnes, G. (2009). How can nature and culture promote health? Scandinavian Journal of Public Health, 37, 559-561. doi:10.1177/1403494809342373

Thagaard, T. (2003). Systematikk og innlevelse. En innføring i kvalitativ metode. Bergen: Fagbokforlaget. 